\title{
Traspasando fronteras con el acceso abierto
}

\section{Crossing borders with open access}

Desde Estudios Atacameños. Arqueología y Antropología Surandinas nos complace presentar el número 57, que busca fortalecer el camino iniciado hace algún tiempo, y a través del cual si bien seguimos sosteniendo una fuerte impronta en el mundo centro y surandino, hemos ido ampliando el área geográfica de cobertura con el afán de derribar fronteras impuestas, que no siempre representan los procesos que ciertamente suceden. Entendemos que aunque existen especificidades nacionales y locales, cada vez más, se impone un carácter compartido, fluido y dinámico de los territorios y los procesos observados en la región sudamericana. Asimismo, buscamos de esta manera fortalecer el intercambio y beneficiar y enriquecer el diálogo tanto entre investigadores como entre centros colectivos de producción de conocimiento científico.

En este número regular, que cubre como siempre los campos de la arqueología, antropología social, historia y bioantropología, ofrecemos 13 artículos que problematizan desde abordajes originales, temas centrales que atañen a debates disciplinares actuales tales como tecnologías y organización social, salud oral en las poblaciones coloniales, arquitectura y materialidad de la interacción social, valoración social y económica del tejido, manifestaciones de religiosidad popular, migración y educación, espacios transfronterizos, relaciones interétnicas y alteridad, etnicidad en procesos de formación estatal, conflictos en torno a la minería, usos de energía solar industrial y manejo de recursos forestales nativos.

Nos satisface informar a nuestros lectores en general y seguidores de la revista, que la misma se ha posicionado en su punto más alto a nivel internacional publicado por el ranking de SCImago (actualizado al año 2018). ${ }^{1}$ Es así que en la actualidad, todas las áreas temáticas identificadas por tal índice, "Anthropology", "Archeology", "Archeology (arts and humanities)", "Cultural Studies" y "History", se encuentran en el nivel de cuartil 1 (Q1) (Figura 1). Asimismo ha aumentado marcadamente el total de citas (Figura 2) y las colaboraciones internacionales (Figura 3).

1 SCImago,(2018).SJR_SCImagoJournal\&CountryRank [Portal]. Recuperado 12.06.2018 http://www.scimagojr.com 


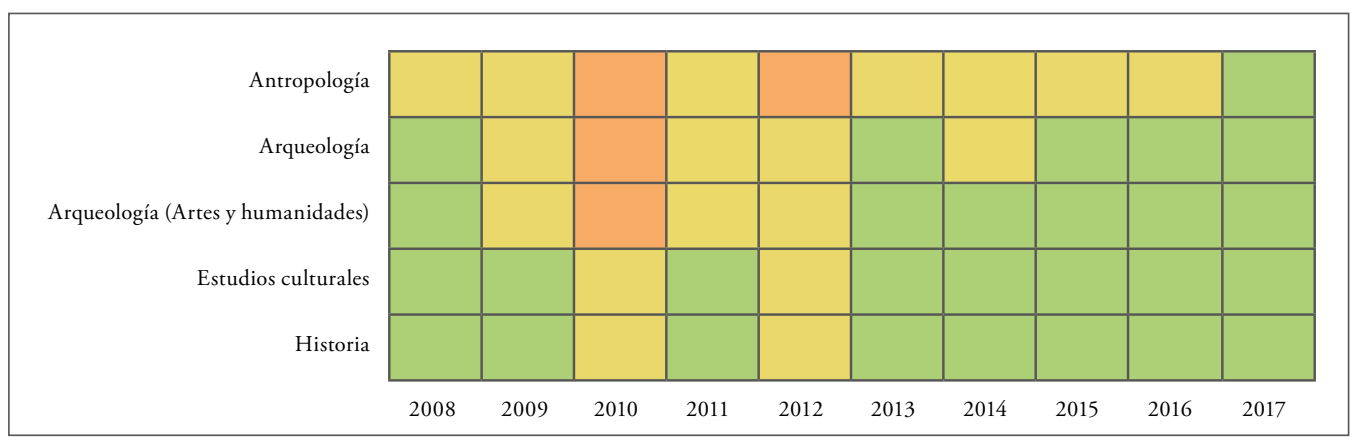

Figura 1. Posicionamiento de Estudios Atacameños en cuartiles.

$$
=\mathrm{Q} 1 \odot=\mathrm{Q} 2 \quad=\mathrm{Q} 3
$$

Fuente: “Quartiles”. SCImago 2018.

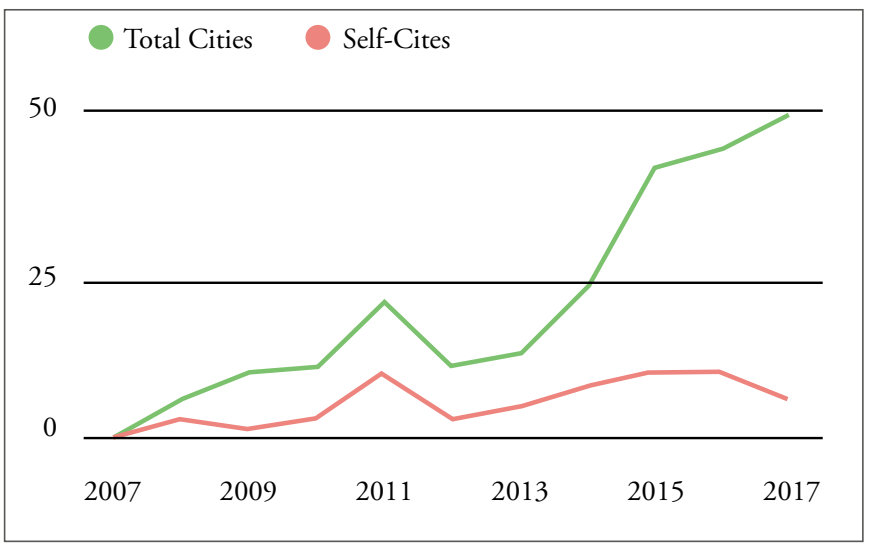

Figura 2. Total de citas. Fuente: SCImago 2018.

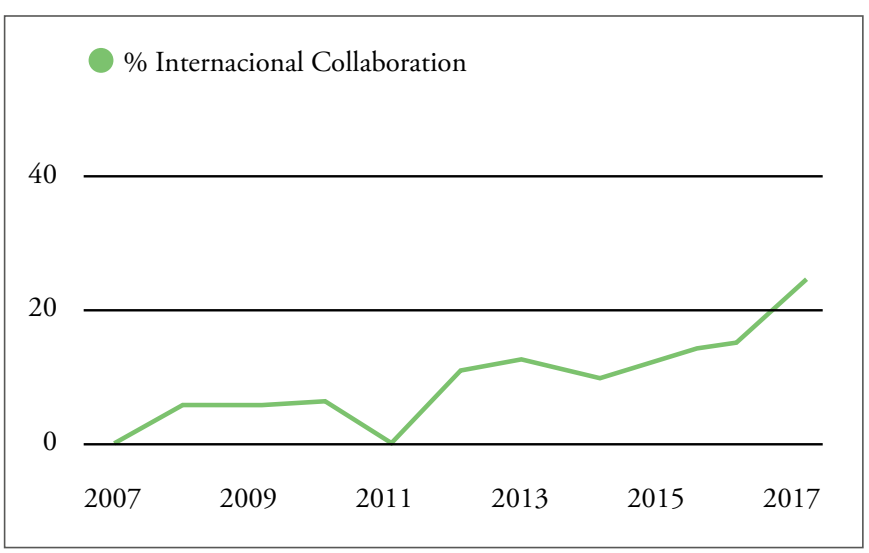

Figura 3. Colaboración internacional. Fuente: SCImago 2018. 
Finalmente, queremos expresar que desde Estudios Atacameños. Arqueología y Antropología Surandinas seguimos apoyando y promoviendo la libre circulación del conocimiento científico a través del Acceso Abierto que permite acceder de inmediato, completa y gratuitamente a todos nuestros artículos, tanto a través de la página de la revista ${ }^{2}$ como de la plataforma SciELO, la cual ofrece todos los volúmenes desde el año 2002 hasta la actualidad. ${ }^{3}$

Los invitamos entonces a recorrer los artículos del presente número, así como a seguir enviándonos colaboraciones que sin duda nos permiten seguir creciendo y mejorando como revista científica.

Dra. Marina Weinberg

Editora General

Instituto de Arqueología y Antropología

Universidad Católica del Norte

San Pedro de Atacama - Chile

marina.weinberg@ucn.cl

2 http://revistas.ucn.cl/index.php/estudios-atacamenos

3 https://scielo.conicyt.cl/scielo.php?script=sci_serial\&pid=0718-1043\&lng=es\&nrm=iso 